\title{
Composite resin color stability: influence of light sources and immersion media
}

\author{
Patricia Aleixo dos Santos DOMINGOS ${ }^{1}$, Patrícia Petromilli Nordi Sasso GARCIA², \\ Ana Luisa Botta Martins de OLIVEIRA ${ }^{3}$, Regina Guenka PALMA-DIBB ${ }^{4}$
}

\begin{abstract}
1- DDS, MSc, PhD, Professor, Department of Dentistry, University Center of Araraquara/UNIARA, Araraquara, SP, Brazil.
2- DDS, MSc, PhD, Professor, Department of Community Dentistry, Araraquara Dental School, São Paulo State University, Araraquara, SP, Brazil.

3- DDS, MSC, Postgraduate student, Department of Pediatric Dentistry, Araraquara Dental School, São Paulo State University, Araraquara, SP, Brazil.

4- DDS, MSc, PhD, Associate Professor, Department of Restorative Dentistry, Ribeirão Preto Dental School, University of São Paulo, Ribeirão Preto, SP, Brazil.
\end{abstract}

Corresponding address: Patrícia Petromilli Nordi Sasso Garcia - Rua Humaitá, 1680 - 14801-903 - Araraquara, SP - Brasil - Phone: +55-16-3301-6405 - Fax: 551633016343 - e-mail: psgarcia@foar.unesp.br

Received: September 7, 2009 - Modification: April 30, 2010 - Accepted: May 25, 2010

\section{ABSTRACT}

\begin{abstract}
$\mathrm{O}$ bjective: This study evaluated the influence of light sources and immersion media on the color stability of a nanofilled composite resin. Material and Methods: Conventional halogen, high-power-density halogen and high-power-density light-emitting diode (LED) units were used. There were 4 immersion media: coffee, tea, Coke ${ }^{\circledR}$ and artificial saliva. A total of 180 specimens ( $10 \mathrm{~mm} \times 2 \mathrm{~mm}$ ) were prepared, immersed in artificial saliva for 24 h at $37 \pm 1{ }^{\circ} \mathrm{C}$, and had their initial color measured with a spectrophotometer according to the CIELab system. Then, the specimens were immersed in the 4 media during 60 days. Data from the color change and luminosity were collected and subjected to statistical analysis by the Kruskall-Wallis test $(p<0.05)$. For immersion time, the data were subjected to twoway ANOVA test and Fisher's test $(p<0.05)$. Results: High-power-density LED $(\Delta E=1.91)$ promoted similar color stability of the composite resin to that of the tested halogen curing units (Jet Lite 4000 plus $-\Delta \mathrm{E}=2.05 ; \mathrm{XL} 3000-\Delta \mathrm{E}=2.28)$. Coffee $(\Delta \mathrm{E}=8.40 ; \Delta \mathrm{L}=-5.21$ ) showed the highest influence on color stability of the studied composite resin. Conclusion: There was no significant difference in color stability regardless of the light sources, and coffee was the immersion medium that promoted the highest color changes on the tested composite resin.
\end{abstract}

Key words: Composite resins. Staining. Dental technology.

\section{INTRODUCTION}

Color stability is an important parameter for modern resin-based filling materials. Several factors influence the color stability of contemporary lightactivated materials, such as the photoinitiator system, the resin matrix, the light-curing unit used for polymerization, and the irradiation times ${ }^{14}$.

The phenomena of sorption and solubility may serve as precursors to a variety of chemical and physical processes that create biological concerns as well as produce deleterious effects on the structure and function of a resin matrix ${ }^{24}$. These effects include swelling, plasticization and softening, oxidation and hydrolysis ${ }^{11}$. As a consequence, there is a decrease of the color stability, promoting higher susceptibility to staining.
Thus, for suitable performance, longevity and good clinical success of esthetic restorations, the material of choice should present adequate intrinsic characteristics ${ }^{3}$ that are specific for each procedure and also that its polymerization is ideal ${ }^{16}$, with this aspect directly related to the light-curing units and their use.

Some light-emitting diode (LED) light-curing units show a similar performance to quartztungsten-halogen curing units, while others seems to be less efficient ${ }^{2}$. These properties included depth of cure (DOC), compressive strength, flexural strength, hardness, and degree of polymerization or double-bond conversion?. However, some researchers have reported lower hardness or lesser degree of double-bond conversion in resin-based composites polymerized using some LED curing 
units ${ }^{15}$ and this was attributed to low power density of $1^{\text {st }}$ generation. For $2^{\text {nd }}$ and $3^{\text {rd }}$ generation of LEDs, these properties were similar to that obtained by the halogen curing units ${ }^{1,5}$.

Color match is one of the most important characteristics of esthetic restorative materials. Color maintenance throughout the functional lifetime of restorations is important for the durability of a treatment ${ }^{23}$.

Composite resin discoloration is multifactorial, including factors such as intrinsic discoloration and extrinsic staining. Nevertheless, a correlation is established between color stability and conversion rate, with incomplete polymerized composite resins showing reduced mechanical properties and greater discoloration susceptibility ${ }^{17}$.

Many studies have shown certain beverages and foods affecting the esthetics as well as the physical properties (microhardness, surface roughness) of composite resins, undermining the quality and longevity of restorations. It may cause a reduction of Knoop microhardness in composite resin after coffee consumption ${ }^{4}$, which suggests that prolonged immersion in a high-temperature solution may lead to significant alterations in certain properties of the composites.

Accordingly, this study investigated the performance of LED technology in comparison to halogen curing units for the photoactivation of an esthetic restorative material regarding its color stability after immersion in different media. Little research is available on the influence of this type of light source on color stability of composite resins when exposed to different media and immersion time.

\section{MATERIAL AND METHODS}

The factors under study were: light sources, at three levels (conventional halogen unit, high-power-density halogen unit and LED) and immersion media at four levels (Coffee, tea, Coke ${ }^{\circledR}$ and artificial saliva). The association between light sources and solutions resulted in 12 groups with 15 specimens each, totalizing 180 specimens. The specimens were randomly distributed using a random numbers table. Each specimen was chosen to compose the experimental groups in the same way. The specimens had their color stability and luminosity evaluated at eight immersion times (TO - $24 \mathrm{~h}$ of immersion in artificial saliva, T1 - after $24 \mathrm{~h}$ of immersion in different media; T2 - after 48 h; T3 - after 7 days; T4 - after 14 days; T5 after 21 days; T6 - after 30 days and T7 - after 60 days). The quantitative response variable was the color change values $(\Delta \mathrm{E})$ and luminosity values $(\Delta \mathrm{L})$, from CIELa*b* system.

A nanofilled composite resin was used (Filtek Supreme XT; 3M/ESPE, St. Paul, MN, USA; shade $\mathrm{B} 1 \mathrm{E})$ (Figure 1), and the light-curing units selected for the study are presented in Figure 2.

The composite resin specimens were randomly subdivided into 4 groups: the control group was maintained in artificial saliva and the three experimental groups were submitted to cycling in selected beverages (Figure 3 ). The specimens were kept immersed in artificial saliva at $37^{\circ} \mathrm{C} \pm 1^{\circ} \mathrm{C}$ in the interval between cycles. The drinks were used in their usual temperature of consumption, i.e., Coke ${ }^{\circledR} \pm 10^{\circ} \mathrm{C}$, tea $\pm 70^{\circ} \mathrm{C}$, and coffee $\pm 70^{\circ} \mathrm{C}$. The temperatures were measured with digital thermometer.

One hundred and eighty samples were prepared using a $10-\mathrm{mm}$ diameter $\times$ 2-mm thick stainless steel mold placed on a glass plate with a transparent polyester strip. These samples were prepared by inserting the composite resin into the mold cavity. To compact and remove the excess material from the sample surfaces, the mold containing the resin was covered with another polyester strip and a glass plate placed on top of it with a $1 \mathrm{~kg}$ weight for $30 \mathrm{~s}$. Next, the weight and the glass plate were removed and the composite resin was light-cured with one of the light curing units selected from the polymer strip for $40 \mathrm{~s}$, and then, the resin specimen was removed from the matrix. The bottom surface of

\begin{tabular}{|l|c|l|c|}
\hline Material & Composition & Particle Type & Mean size (load) \\
\hline FiltekTM Supreme XT & Bis-GMA & Non-agglomerated primary & 0.6 to $1.4 \mu \mathrm{m}$ \\
Nanofilled composite resin & Bis-HEMA & silica $(75 \mathrm{\eta m})$ & $75 \mathrm{\eta m}$ \\
3M/ESPE & TEGDMA & Silica agglomerate $(75 \mathrm{\eta m})$ & \\
\hline
\end{tabular}

Figure 1- Composite resin characteristics

\begin{tabular}{|l|c|c|c|c|}
\hline Light-Curing Unit & Wavelength & Light Source & Power Density & Light Tip \\
\hline XL 3000, 3M/ESPE & 400 to $500 \mathrm{~nm}$ & Halogen & $480-530 \mathrm{~mW} / \mathrm{cm}^{2}$ & $8 \mathrm{~mm}$ \\
\hline Jet Lite 4000 Plus, J Morita & $500 \mathrm{~nm}$ & Halogen & $1230 \mathrm{~mW} / \mathrm{cm}^{2}$ & $8 \mathrm{~mm}$ \\
\hline Ultralume LED 5, Ultradent & 450 to $480 \mathrm{~nm}$ & LED & $790 \mathrm{~mW} / \mathrm{cm}^{2}$ & $11 \mathrm{~mm}$ \\
\hline
\end{tabular}

Figure 2- Description of tested light curing units 


\begin{tabular}{|c|c|c|c|c|}
\hline $\begin{array}{l}\text { Beverage } \\
\text { (Brand) }\end{array}$ & Composition & $\mathrm{pH}$ & Manufacturer & Lot \\
\hline Artificial Saliva & $\begin{array}{c}\mathrm{KH}_{2} \mathrm{PO}_{4}, \mathrm{~K}_{2} \mathrm{HPO}_{4}, \mathrm{KCl}, \mathrm{NaCl}, \mathrm{MgCl}_{2} \cdot 6 \mathrm{H}_{2} \mathrm{O}, \mathrm{CaCl}_{2} \cdot 2 \mathrm{H}_{2} \mathrm{O}, \mathrm{NaF} \\
\text { sorbitol, nipagin, nipasol, carboxymethylcellulose } \\
(\mathrm{CMC}), \text { water }\end{array}$ & 7.0 & $\begin{array}{l}\text { Laboratory of } \\
\text { Biochemistry of } \\
\text { FCFRP-USP }\end{array}$ & - \\
\hline $\begin{array}{l}\text { Coffee } \\
\text { (Pilão®) }\end{array}$ & $\begin{array}{l}\text { Caffeine, mineral as potassium }(\mathrm{K}) \text {, magnesium }(\mathrm{Mg}) \text {, } \\
\text { calcium }(\mathrm{Ca}) \text {, sodium }(\mathrm{Na}) \text {, iron }(\mathrm{Fe}) \text {, manganese }(\mathrm{Mn}) \text {, } \\
\text { rubidium }(\mathrm{Rb}) \text {, zinc }(\mathrm{Zn}) \text {, copper }(\mathrm{Cu}) \text {, strontium }(\mathrm{Sr}) \text {, } \\
\text { chromium }(\mathrm{Cr}) \text {, vanadium }(\mathrm{V}) \text {, barium }(\mathrm{Ba}) \text {, nickel }(\mathrm{Ni}) \text {, } \\
\text { cobalt }(\mathrm{Co}) \text {, lead }(\mathrm{Pb}) \text {, molybdenum }(\mathrm{Mo}) \text {, titanium }(\mathrm{Ti}) \\
\text { and cadmium }(\mathrm{Cd}) \text {, amino acids, lipids, sugars, vitamin B } \\
\text { complex and chlorogenic acids }\end{array}$ & 6.8 & $\begin{array}{l}\text { Pilão - Sara Lee } \\
\text { Cafés do Brasil } \\
\text { Ltda }\end{array}$ & $302 a$ \\
\hline $\begin{array}{l}\text { Yerba Mate } \\
\text { Tea (Mate } \\
\text { Leaoß) }\end{array}$ & $\begin{array}{l}\text { Leaves and stems of toasted mate (llex paraguariensis) also } \\
\text { contained alkaloids (caffeine, methylxanthine, theophylline } \\
\text { and theobromine), tannins (folic acid and caffeic), vitamins } \\
\text { (A, Bi, B2, C and E), minerals (aluminum, calcium, } \\
\text { phosphorus, iron, magnesium, manganese and potassium), } \\
\text { protein (essential amino acids), glucose (fructose, glucose, } \\
\text { sucrose and raffinose), lipids (essential oils and substances } \\
\text { CERAC), and cellulose, dextrin, saccharin and gums }\end{array}$ & 6.5 & Leão Junior SA & 060/06 \\
\hline $\begin{array}{l}\text { Soft Drink } \\
\text { (Coke }{ }^{\circledR} \text { - } \\
\text { normal) }\end{array}$ & $\begin{array}{l}\text { carbonated water, sugar, extract of cola nuts, caffeine, } \\
\text { caramel color, acidulant INS } 338 \text {, carbohydrates and sodium }\end{array}$ & 2.62 & & P181207 \\
\hline
\end{tabular}

Figure 3- Tested beverages

the specimen was identified using a scalpel blade. There was no polishing on the specimen surface because most of the superficial smoothness was obtained with the polyester strip ${ }^{13}$. It is important to emphasize that the light tip of curing units had compatible size with the specimens' diameter to obtain complete polymerization of composite resin.

The color of the specimens was analyzed with a portable colorimetric spectrophotometer (Color guide 45/0, PCB 6807 BYK-Gardner GmbH Gerestsried, Germany) using an optical geometry of $45^{\circ} / 0^{\circ}$. The color was evaluated according to the color system CIELa*b*, in which L indicates color luminosity (ranging from 0 to 100 , that means black to white); a* determines the amount of red (positive values) and green (negative values); b* determines the amount of yellow (positive values) and blue (negative values).

Color change was obtained through Hunter equation $\Delta \mathrm{E}_{\mathrm{ab}} *=\left[\left(\Delta \mathrm{L}^{*}\right)^{2}+(\Delta \mathrm{a} *)^{2}+\left(\Delta \mathrm{b}^{*}\right)^{2}\right]^{1 / 2}$, while luminosity values $\left(\Delta \mathrm{L}^{*}\right)$, were reached using $\Delta \mathrm{L}^{*}=\mathrm{L}^{*}(\mathrm{tx})-\mathrm{L}^{*}(\mathrm{t} 0)$, where (tx) represents immersion time and (to) baseline. The literature is not in agreement with respect to the limitations of the human eye in terms of acknowledging differences in color, considering that this limit differs from individual to individual ${ }^{8}$. The adopted classification of $\Delta \mathrm{E}$ values was determined by the National Bureau of Standards (NBS) that considers: 0.0 to 0.5 values: extremely slight change; 0.5 to
1.5: slight change; 1.5 to 3.0: perceivable change; 3.0 to 6.0 : marked change; 6.0 to 12.0 : extremely marked change; 12.0 or more: change to another color ${ }^{7}$.

To determine the statistical method to analyze the data concerning the color and light change, the normal curve adherence test was performed to verify the sample distribution regarding its normality. As data distribution was not normal, the non-parametric Kruskal-Wallis test was used for comparison of the light source factors and immersion media. Regarding the immersion time, each subgroup was analyzed separately according to the immersion media to study the color variation with time. As data distribution was normal and homoscedastic, two-way ANOVA (immersion medium and immersion time, with 1 linked factor), and Fisher's exact test were used. A significance level of $5 \%$ was set for all analyses.

\section{RESULTS}

Table 1 shows the mean standard errors of the color $(\Delta \mathrm{E})$ and light $(\Delta \mathrm{L})$ change of the specimens, according to the light sources.

Considering the light source factor alone, Table 1 shows that there was a statistically significant difference between the light-curing units, with Ultralume LED 5 showing less color change $(\Delta E)$ when compared to the XL3000, and similar to Jet 
Lite 4000 Plus (J Morita Corporation, Tarumi-cho Suita City, Osaka, Japan), with the last two similar to each other $(p<0.05)$.

Regarding the light sources, the light-curing units Ultralume LED 5 and XL 3000 (3M/ESPE, St. Paul, MN, USA) showed less change when compared to Jet Lite Plus 4000, which had a negative value of $\Delta \mathrm{L}$.

Table 2 shows the means and standard errors of color $(\Delta \mathrm{E})$ and light $(\Delta \mathrm{L})$ change analyzed by the different immersion media.

Considering only the immersion media, there was influence of the medium in the color change of the material. The color change $(\Delta \mathrm{E})$ results showed that the Coke ${ }^{\circledR}$ medium was the one that least affected the composite resin color, indicating a statistically different mean value, and lower than the other mediums. The artificial saliva and tea showed intermediate color change values, which were statistically similar to each other and different from the coffee values, which showed the highest $\Delta \mathrm{E}$ value.

Regarding the light change in the material, all elements were statistically different, with coffee

Table 1- Mean and standard error for color and light changes depending on the light sources

\begin{tabular}{lcccc}
\hline Light Source & \multicolumn{2}{c}{ Color Change $(\Delta \mathrm{E})$} & \multicolumn{2}{c}{${\text { Light Change }(\Delta \mathrm{L})^{*}}^{*}$} \\
& Mean & Standard Error & Mean & Standard Error \\
\hline Ultralume LED 5 & $1.91^{\mathrm{a}}$ & 0.2224 & $0.11^{\mathrm{a}}$ & 0.2173 \\
Jet Lite 4000 Plus & $2.05^{\mathrm{ab}}$ & 0.2513 & $-0.23^{\mathrm{b}}$ & 0.2293 \\
XL 3000 & $2.28^{\mathrm{b}}$ & 0.2422 & $0.01^{\mathrm{a}}$ & 0.2573 \\
\hline
\end{tabular}

$\Delta E-g L=2 ; H=6.343928 ; p=0.041920$

$\Delta \mathrm{L}-\mathrm{gL}=2 ; \mathrm{H}=8.291655 ; \mathrm{p}=0.015830$

Similar letters indicate vertical statistical similarity (column).

Table 2- Mean and standard error for color and light changes according to the immersion media

\begin{tabular}{lcccc}
\hline Immersion Media & \multicolumn{2}{c}{ Color Change $(\Delta \mathrm{E})$} & \multicolumn{2}{c}{ Light Change $(\Delta \mathrm{L})$} \\
& Mean & Standard Error & Mean & Standard Error \\
\hline Artificial Saliva & $1.73^{\mathrm{b}}$ & 0.2375 & $0.96^{\mathrm{a}}$ & 0.2562 \\
Coffee & $8.40^{\mathrm{c}}$ & 0.3198 & $-5.21^{\mathrm{d}}$ & 0.3168 \\
Tea & $2.13^{\mathrm{b}}$ & 0.1960 & $-0.48^{\mathrm{c}}$ & 0.1541 \\
Coke $^{\circledR}$ & $1.43^{\mathrm{a}}$ & 0.0983 & $0.36^{\mathrm{b}}$ & 0.1264 \\
\hline
\end{tabular}

$\Delta E-g L=3 ; H=423.0867 ; p=0.000000$

$\Delta \mathrm{L}-\mathrm{gL}=3 ; \mathrm{H}=475.5569 ; \mathrm{p}=0.000000$

Similar letters indicate vertical statistical similarity (column).

Table 3- Distribution of means and standard deviations (SD) of color change $(\Delta \mathrm{E})$ and light $(\Delta \mathrm{L})$ of the studied composite resin as a function of the time $\mathrm{x}$ immersion medium interaction

\begin{tabular}{|c|c|c|c|c|c|c|c|c|}
\hline \multirow{2}{*}{$\begin{array}{c}\text { Immersion } \\
\text { time }\end{array}$} & \multicolumn{4}{|c|}{ Color Change $(\Delta E)$} & \multicolumn{4}{|c|}{ Light $(\Delta \mathrm{L})$} \\
\hline & $\begin{array}{l}\text { Artificial } \\
\text { saliva }\end{array}$ & Coffee & Tea & Coke ${ }^{\circledR}$ & $\begin{array}{l}\text { Artificial } \\
\text { saliva }\end{array}$ & Coffee & Tea & Coke ${ }^{\circledR}$ \\
\hline & Average (SD) & Average (SD) & Average (SD) & Average (SD) & Average (SD) & Average (SD) & Average (SD) & Average (SD) \\
\hline $24 \mathrm{~h}$ & $1.22^{\mathrm{a}}( \pm 0.68)$ & $3.11^{\mathrm{a}}( \pm 3.80)$ & $1.10^{\mathrm{a}}( \pm 0.85)$ & $1.34^{\mathrm{a}}( \pm 1.31)$ & $0.26^{a}( \pm 1.00)$ & $0.14^{a}( \pm 2.75)$ & $0.38^{\mathrm{a}}( \pm 1.23)$ & $-0.15^{a}( \pm 1.62)$ \\
\hline $48 \mathrm{~h}$ & $1.42^{\mathrm{a}}( \pm 1.19)$ & $4.03^{\mathrm{a}}( \pm 5.10)$ & $1.24^{\mathrm{a}, \mathrm{b}}( \pm 1.04)$ & $1.39^{\mathrm{a}}( \pm 1.38)$ & $0.17^{\mathrm{a}}( \pm 1.53)$ & $-0.79^{\mathrm{a}}( \pm 8.10)$ & $-0.14^{\mathrm{a}, \mathrm{b}}( \pm 1.49)$ & $0.29^{a, b}( \pm 1.69)$ \\
\hline $7 d$ & $1.53^{\mathrm{a}}( \pm 0.65)$ & $7.27^{\mathrm{b}} \quad( \pm 1.31)$ & $1.94^{b}( \pm 0.27)$ & $1.61^{a}( \pm 0.51)$ & $0.67^{\mathrm{a}}( \pm 1.03)$ & $-3.49^{b}( \pm 7.57)$ & $-0.76^{a, b}( \pm 0.59)$ & $0.52^{\mathrm{a}, \mathrm{b}}( \pm 0.87)$ \\
\hline $14 d$ & $2.43^{\mathrm{a}, \mathrm{b}}( \pm 2.48)$ & $9.22^{\mathrm{c}}( \pm 2.78)$ & $1.94^{b}( \pm 0.81)$ & $2.03^{a, b}( \pm 1.79)$ & $1.55^{\mathrm{a}, \mathrm{b}}( \pm 2.75)$ & $-4.89^{b, c}( \pm 4.19)$ & $-0.51^{\mathrm{a}, \mathrm{b}, \mathrm{c}}( \pm 1.46)$ & $0.55^{\mathrm{a}}( \pm 2.33)$ \\
\hline $21 d$ & $3.52^{\mathrm{b}, \mathrm{c}}( \pm 3.80)$ & $10.44^{c}( \pm 3.39)$ & $3.00^{c}( \pm 1.16)$ & $1.91^{\mathrm{a}}( \pm 1.40)$ & $2.95^{\mathrm{b}, \mathrm{c}}( \pm 3.99)$ & $-5.83^{c}( \pm 4.20)$ & $0.60^{\mathrm{a}, \mathrm{b}, \mathrm{c}}( \pm 2.18)$ & $1.03^{b}( \pm 1.75)$ \\
\hline $30 \mathrm{~d}$ & $3.80^{\circ} \quad( \pm 3.31)$ & $12.42^{\mathrm{d}}( \pm 4.05)$ & $4.95^{d}( \pm 1.96)$ & $1.94^{\mathrm{a}}( \pm 1.42)$ & $3.11^{\mathrm{c}}( \pm 3.59)$ & $-7.59^{d}( \pm 4.40)$ & $-0.99^{b}( \pm 2.28)$ & $0.70^{\mathrm{a}}( \pm 1.96)$ \\
\hline $60 \mathrm{~d}$ & $9.25^{d}( \pm 6.66)$ & $17.49^{\mathrm{e}}( \pm 4.98)$ & $10.19^{e}( \pm 3.03)$ & $2.66^{\mathrm{b}}( \pm 2.77)$ & $8.74^{\mathrm{d}}( \pm 7.18)$ & $-11.31^{\mathrm{e}}( \pm 5.60)$ & $-2.53^{d}( \pm 5.17)$ & $-0.66^{a, c}( \pm 3.66)$ \\
\hline
\end{tabular}

Similar letters indicate vertical statistical similarity (column) 
promoting the greatest change of these optical properties, with negative $\Delta \mathrm{L}$ followed by tea media, while for the saliva and Coke $^{\circledR}$, the specimens showed positive values of $\Delta \mathrm{L}$.

The interaction of the factors time $\mathrm{x}$ immersion medium on the color and light change of the composite resin are shown in Table 3.

There were statistically significant differences between the $\Delta \mathrm{E}$ values in the time comparison of $24 \mathrm{~h}$ and 60 days of immersion for all studied media (Table 2). Note that this assessment was performed intragroup and not intergroup. Among the media tested, Coke ${ }^{\circledR}$ showed the lowest values of $\Delta E$ as a function of time and coffee presented the highest values.

Regarding the light change, Table 3 shows that, in general, comparing the initial ( $24 \mathrm{~h}$ ) and the final (60 days) $\Delta \mathrm{L}$ values, only Coke ${ }^{\circledR}$ did not present a statistically significant difference of that property over time. It is also important to emphasize that of the four studied media, the one that showed the lowest values of $\Delta L$ was Coke ${ }^{\circledR}$, followed by tea, while coffee was the one that showed the highest changes.

Regarding the artificial saliva, it was observed that by the $14^{\text {th }}$ day of immersion, the values of $\Delta \mathrm{E}$ were statistically similar. The highest changes were observed after 21 days, showing a statistically significant difference when compared to the $60^{\text {th }}$ day. Regarding light, little change was observed up to 21 days, increasing at times of 30 and 60 days of immersion.

The $\Delta \mathrm{E}$ values of coffee were similar up to $48 \mathrm{~h}$ of immersion, and presented a statistically significant difference between $48 \mathrm{~h}$ and 7 days, 7 and 14 days, 21 and 30 days, and 30 and 60 days. $\Delta \mathrm{L}$ showed similar behavior to that of $\Delta \mathrm{E}$.

Similar $\Delta \mathrm{E}$ values of tea were found between 24 and $48 \mathrm{~h}$ and $48 \mathrm{~h}$ to 14 days. The immersion times of 21,30 and 60 days showed different $\Delta \mathrm{E}$ values among themselves and also different when compared to the previous time frames. Also, there were similar light values up to 21 days of immersion, but for times of 30 and 60 days, these values increased significantly.

For Coke ${ }^{\circledR}$, there was a statistically significant difference in color change $(\Delta \mathrm{E})$ only at the end of experiment (60 days of immersion), while for light, there was little change observed at the time of 21 days, with the other times remained similar to each other.

\section{DISCUSSION}

Composite resins are restorative materials that have been widely adopted for esthetic procedures due to their excellent properties and power of union to enamel and dentin. However, one of their disadvantages is the color change with time, which is a major reason for replacing restorations ${ }^{25}$. There are many extrinsic and intrinsic factors that influence color stability of composite resins ${ }^{14,18,20,25,29}$. In this study, the light source and immersion medium were analyzed as influential factors to optical alterations of a resin.

It is known that the efficiency of polymerization may influence discoloration, since the higher degree of conversion, the smaller the amount of residual monomers available to form colored degraded products $^{23}$. Observing light sources as an isolated factor, it was noted that this might cause color alteration to the studied composite resin. The LED unit showed the lowest color alteration $(\Delta \mathrm{E}=1.91)$ when compared to QTH units (XL3000 - $\Delta \mathrm{E}=2.28$ and Jet Lite $-\Delta \mathrm{E}=2.05)$. However, any light source presented significant color changes ${ }^{18}$. This probably occurred because the light source interfered with the effectiveness of the polymeric conversion ${ }^{22}$, because the quality of the polymerization reaction associated to the composition of the resin matrix and the degree of conversion of the photoinitiator ${ }^{14}$ are the elements responsible for the aesthetic restorative materials' color stability. Results of this study were similar to those found by Pires-deSouza, et al.22 (2007), who found that the tested LED equipment also showed lower color changes for a hybrid resin, when compared to a conventional halogen unit. Nevertheless, a research ${ }^{31}$ showed no statistically significant difference in the color change results when the different types of light sources were compared. In addition, Soares, et al. ${ }^{25}$ (2007) observed chemical changes in the resinous matrix of the resins polymerized by LED, which produced more staining of the composite when that device was compared to the halogen light source.

Although the technology of LED curing units has been widely studied, there are few studies in literature comparing the influence of this light source and and halogen lamps on the color stability of composite resins ${ }^{1,2}$. This fact contributes to the lack of consensus about the equipment that produces the best results. In this study, it is believed that the advantage of LED over conventional halogen lamp was because we used a high-power density LED unit $\left(790 \mathrm{~mW} / \mathrm{cm}^{2}\right)$, which according to Bala, Ölmez and Kalayci ${ }^{5}$ (2005) promotes a higher degree of monomer conversion and hence better results. In the aforementioned works, low and mean power density LED sources (130-175 $\mathrm{mW} / \mathrm{cm}^{2}$ and $285 \mathrm{~mW} / \mathrm{cm}^{2}$, respectively) were used. Another important factor is that LED has more spectral purity than the conventional one, as it has a narrow band of light emission with a wavelength between 450 and $490 \mathrm{~nm}$, with peak emission at $470 \mathrm{~nm}$, and this is the coincident blue light band with the absorption spectrum of most of the photoinitiators included in 
the composite resins, which allows full use of the light emitting diodes ${ }^{19}$. Moreover, the process of obtaining light energy and its use by LEDs is greater than that of the halogen lamp, given that this can only convert $1 \%$ of the total energy produced into light, while the rest is dissipated in the form of heat, which can cause adverse thermal effects ${ }^{5}$.

Besides the color change, the light source also affected the light change of the resin studied, drawing attention to the negative value for Jet Lite $(\Delta \mathrm{L}=-0.23)$.

As Jet Lite is a high-power halogen light device (greater power than Ultralume 5 and XL3000), during the accelerated curing, it can promote the formation of polymer chains with lower molecular weight and residual monomers and, consequently, partial polymerization of the material, with part of the photoinitiator remaining idle. Camphoroquinone, which is the photoinitiator of Filtek Supreme, has a yellow coloring and its color changes when photoactivated, thus becoming "transparent". However, when the irradiation is not sufficient, a small amount of camphoroquinone remains inactive, causing a residual yellow in the final color of the composite resin, which may give a darker color to the material and this could be one of the factors that might have interfered in the composite resin light when photoactivated by the unit ${ }^{14,22}$. Therefore, the light source is an important factor to be taken into account when an esthetic restoration is performed with composite resin. Nevertheless, this is not the only factor that influences the color stability of this material, taking into account other aspects, such as the means of imersion ${ }^{16,21}$. Additional polymerization is not efficient for all materials and can be compensated by cross-linking reactions extending for 1 week after initial photoactivation ${ }^{15}$.

In this case, in general only coffee surpassed the clinical acceptable limit, considering this an extremely perceptive change, while the other immersion media promoted slightly perceptible changes (saliva and tea) or imperceptible changes $\left(\text { Coke }{ }^{\circledR}\right)^{18}$.

Comparing the results of this work with those of Patel, et al. ${ }^{21}$ (2004), the values of $\Delta E$ found for the specimens immersed in coffee were higher, however, those subjected to $\operatorname{Coke}^{\circledR}$, were similar. Ertas, et al. ${ }^{10}$ (2006), comparing the immersion of the composite resin Filtek Supreme in various media (coffee, tea, red wine, Coke ${ }^{\circledR}$ and water), found that both water and Coke ${ }^{\circledR}$ showed a mild color change, while tea, coffee and wine had greater influence on the staining of this material. However, Fontes, et al. ${ }^{12}$ (2009) observed that after 1 week of immersion in coffee, yerba mate or water, specimens did not show significant differences for $\Delta \mathrm{E}$ values from the baseline, but the group immersed in grape juice presented significant color change on the nanofill composite resin studied. In addition, Tunc, et al. ${ }^{27}$ (2010) observed that among various children's drinks in contact with microhybrid composites, cola drink was able to promote the highest color change compared with grape juice, chocolate milk and distilled water.

According to this study, the artificial saliva also promoted a slight color change in the specimens $(\Delta E=1.73)$, classified as slightly perceptible ${ }^{18}$. The same result was obtained by Omata, et al. ${ }^{20}$ (2006), when comparing the color change of composite resin specimens immersed in distilled water and artificial saliva, which observed that the distilled water group did not undergo any color change, while the artificial saliva did.

Besides the light source and immersion medium, another factor to be considered in the color stability of the composite resin is the immersion time. This was also observed in the present research. However, the analysis of immersion time alone showed that the most pronounced color change occurred after 30 days and not in the initial hours. This finding disagrees with those of a previous work ${ }^{6}$, which showed that the composite resins evaluated underwent greater staining in the first $24 \mathrm{~h}$ and 7 days. This discrepancy can be attributed to the difference among the methodologies. In all studies cited in this work, the specimens were immersed in their respective immersion media during the entire experiment. However, in his work, as well as that performed by Garcia, et al. ${ }^{13}$ (2008), a clinical situation was simulated and accordingly the sample specimens were immersed in their immersion media for 15 min daily. Analyzing the interaction between the factors in this work (light source and immersion medium) and time, it can be observed that the immersion medium was the one that influenced the color change of the composite resin.

For coffee, there was a color change in the resin since the first $24 \mathrm{~h}$ of immersion, similar to that observed by Yazici, et al. ${ }^{30}$ (2007), when the same composite resin was examined. This change progressed at each evaluation period until reaching the value of $\Delta E=17.49$ after 60 days, which, according to the classification issued by the National Bureau of Standards - $\mathrm{NBS}^{7}$, means changing to another color. Although there was also a significant color change in the specimens immersed in tea, they underwent minor color change until 30 days and only changed in the period from 30 days to 60 days of immersion, when the $\Delta \mathrm{E}$ ranged from 4.95 to 10.19 . Yazici, et al. ${ }^{30}$ (2007) observed the same behavior for tea. Regarding the time of immersion, the artificial saliva also influenced significantly the color stability of the composite resin $\left(\Delta \mathrm{E}_{24 \mathrm{~h}}=1.22\right.$; $\Delta \mathrm{E}_{60 \text { days }}=9.25$ ). In contrast, Coke ${ }^{\circledR}$ was the medium that had the lowest influence on the color stability 
of the composite resin $\left(\Delta \mathrm{E}_{24 \mathrm{~h}}=1.34 ; \Delta \mathrm{E}_{60 \text { days }}=2.66\right)$.

According to Soares, et al. ${ }^{25}$ (2007) and Villalta, et al. ${ }^{29}$ (2006), the staining capacity of the composite resin is related to extrinsic factors, such as the pigment agent is subjected to, and to intrinsic factors, such as loading particles and resinous matrix. In this study, the extrinsic factors related to color change were observed. However, the intrinsic factors cannot be left aside, since a recently developed composite resin was used. Topcu, et al. ${ }^{26}$ (2009) has shown that the effect of the staining solutions might be different for distinct materials and found that a nanofilled composite resin (Filtek Supreme) had the least discoloration among other tested composite materials (Filtek Z250, Charisma and Quadrant).

The structure of the composite resin and the characteristics of its particles have a direct impact on its surface smoothness and its susceptibility to staining by external agents. In this work, the composite resin Filtek Supreme was studied, which is a nanocomposite containing primary silica particles of $20 \mathrm{~nm}$ and silica/zirconia nanoagglomerates with size ranging from $0.6 \mu \mathrm{m}$ to $1.4 \mu \mathrm{m}$. Their resinous matrix is composed of Bis-GMA, UDMA, Bis-EMA and TEGDMA ${ }^{29}$. The cluster of particles - nanoclusters - found in Filtek Supreme, seems to produce less resistance to color change than the micrometric particles of silicazirconia found in microhybrid resins, and this can provide a high susceptibility feature to the water absorption of the studied resin ${ }^{10}$. UDMA is more resistant to staining than the Bis-GMA due to its low sorption and water solubility characteristics. In the microhybrid resin system, the main components are Bis-GMA, UDMA and Bis-EMA. In addition to these, there is still a small amount of TEGDMA, hydrophilic monomer, mixed with the UDMA and Bis-EMA, promoting a hydrophobicity characteristic to the composite resin. Filtek Supreme has the same resinous matrix formulation as Filtek Z250 and P60 (both microhybrids), but has a greater amount of TEGDMA, which only Bis-GMA mixed in it. According to Ertas, et al. ${ }^{10}$ (2006), this seems to be the factor responsible for its high water absorption and greater susceptibility to staining. Although in this work Filtek Supreme was not compared to other types of composite resin, the hypothesis can be raised that the high staining caused by coffee, tea and artificial saliva may have also occurred due to the aforementioned characteristics of this new resin. Thus, although the nanoparticled composite resins were developed to improve the physical and optical properties of the composite, there are still few studies in this regard, hence suggesting that their performance should be further and better studied.

This in vitro study provided information on the color stability of a direct esthetic restorative material when photopolymerized by different light sources and subjected to immersion in various media. The obtained results are intended to help professionals working with esthetic dentistry in order to alert them of the need to choose the most favorable light source for each type of restorative material and patient, taking into account their eating habits and consumption of beverages containing dyes. A future research could be developed with an in vivo sample to simulate clinical reality.

\section{CONCLUSION}

Based on the employed methodology and the obtained results, it may be concluded that:

There was no significant difference between light sources on promoting changes of color stability of the composite resin;

Coffee was the tested immersion medium that had the most influence on color stability of the composite resin, followed by tea;

The immersion time gradually influenced the color stability of the composite resin up to 30 days of immersion, with the highest activity observed in the 30 to 60 day period.

\section{REFERENCES}

1- Aravamudhan K, Floyd CJE, Rakowski D, Flaim G, Dickens SH, Eichmiller FC, et al. Light-emitting diode curing light irradiance and polymerization of resin-based composite. J Am Dent Assoc. 2006;137:213-37

2-Aravamudhan K, Rakowski D, Fan PL. Variation of depth of cure and intensity with distance using LED curing lights. Dent Mater. 2006;22:988-94.

3- Asmussen E. Factors affecting the color stability of restorative resins. Acta Odontol Scand. 1983;41:11-8.

4- Badra VV, Faraoni JJ, Ramos RP, Palma-Dibb RG. Influence of different beverages on the microhardness and surface roughness of resin composites. Oper Dent. 2005;30:213-9.

5- Bala O, Olmez A, Kalayci S. Effect of LED and halogen light curing on polymerization of resin-based composites. J Oral Rehabil. 2005;32:134-40.

6- Buchalla W, Attin T, Hilgers RD, Hellwig E. The effect of water storage and light exposure on the color and translucency of a hybrid and a microfilled composite. J Prosthet Dent. 2002;87:26470 .

7- Central Bureau of the International Commission on Illumination. Colorimetry. Vienna: CIE Publication; 1986. p.30.

8- Douglas RD, Brewer JD. Acceptability of shade differences in metal ceramic crowns. J Prosthet Dent. 1998;79:254-60.

9- El-Mowafy O, El-Badrawy W, Wasef M, Omar H, Kermanshahi S. Efficacy of new LED light-curing units in hardening of Class II composite restorations. J Can Dent Assoc. 2007;73:253.

10- Ertaş E, Güler AU, Yücel AÇ, Köprülü H, Güler E. Color stability of resin composites after immersion in different drinks. Dent Mater J. $2006 ; 25: 371-6$.

11- Ferracane JL. Hygroscopic and hydrolytic effects in dental polymer networks. Dent Mater. 2006;22:211-22.

12- Fontes ST, Fernández MR, Moura CM, Meireles SS. Color stability of a nanofill composite: effect of different immersion media. J Appl Oral Sci. 2009;17:388-91. 
13- Garcia PPNS, Neto ER, Santos PA, Campos JADB, Dibb RGP. Influence of the surface sealant on the translucency of composite resin: effect of immersion time and immersion media. Mater Res. 2008;11:193-7.

14- Janda R, Roulet JF, Latta M, Steffin G, Rüttermann S. Color stability of resin-based filling materials after aging when cured with plasma or halogen light. Eur J Oral Sci. 2005;113:251-7.

15- Knezević A, Tarle Z, Meniga A, Sutalo J, Pichler G, Ristić M. Degree of conversion and temperature rise during polymerization of composite resin samples with blue diodes. J Oral Rehabil. 2001;28:586-91.

16- Kolbeck C, Rosentritt M, Lang R, Handel G. Discoloration of facing restorative composites by UV-irradiation and staining food. Dent Mater. 2006;22:63-8.

17- Micali B, Basting RT. Effectiveness of composite resin polymerization using light-emitting diodes (LEDs) or halogenbased light-curing units. Braz Oral Res. 2004;18:266-70.

18- Mutlu-Sagesen L, Ergün G, Ozkan Y, Semiz M. Color stability of a dental composite after immersion in various media. Dent Mater J. 2005;24:382-90.

19- Nomoto R. Effect of light wavelength on polymerization of light-cured resins. Dent Mater J. 1997;16:60-73.

20- Omata Y, Uno S, Nakaoki Y, Tanaka T, Sano H, Yoshida S, et al. Staining of hybrid composites with coffee, oolong tea, or red wine. Dent Mater J. 2006;25:125-31.

21- Patel SB, Gordan VV, Barret AA, Shen C. The effect of surface finishing and storage solutions on the color stability of resin-based composites. J Am Dent Assoc. 2004;135:587-94.
22- Pires-de-Souza FC, Garcia LF, Hamida HM, Casemiro LA. Color stability of composites subjected to accelerated aging after curing using either a halogen or a Light Emitting Diode source. Braz Dent J. 2007; 18:119-23.

23- Samra APB, Pereira SK, Delgado LC, Borges CP. Color stability evaluation of aesthetic restorative materials. Braz Oral Res. 2008;22:205-10.

24- Sideridou ID, Karabela MM, Vouvoudi ECh. Dynamic thermomechanical properties and sorption characteristics of two commercial light cured dental resin composites. Dent Mater. 2008;24:737-43.

25- Soares LES, Cesar ICR, Santos CGC, Cardoso AL, Liporoni PCS, Munin $E$, et al. Influence of coffee on reflectance and chemistry of resin composite protected by surface sealant. Am J Dent. 2007;20:299-304.

26- Topcu FT, Sahinkesen G, Yamanel K, Erdemir U, Oktay EA, Ersahan S. Influence of different drinks on the colour stability of dental resin composites. Eur J Dent. 2009;3:50-6.

27- Tunc ES, Bayrak S, Guler AU, Tuloglu N. The effects of children's drinks on the color stability of various restorative materials. J Clin Pediatr Dent. 2009;34:147-50.

28- Usumez A, Ozturk N, Ozturk B. Two-year color changes of light-cured composites: influence of different light-curing units. Oper Dent. 2005;30:655-60.

29- Villalta P, Lu H, Okte Z, Garcia-Godoy F, Powers JM. Effects of staining and bleaching on color change of dental composite resins. J Prosthet Dent. 2006;95:137-42.

30- Yazici AR, Celik C, Dayangaç B, Ozgünaltay G. The effect of curing units and staining solutions on the color stability of resin composites. Oper Dent. 2007;32:616-22. 